\title{
Hvorfor er resultater fra organisert mammografiscreening så vanskelig å tolke?
}

\author{
Mammografiscreening er debattert i vitenskapelige tidskrifter og i mediene de siste tiår. Forskerne er uenige \\ om hvor store fordeler og ulemper screeningen innebærer. Det er en rekke metodiske utfordringer knyttet til \\ evaluering av mammografiscreening. Jeg vil her beskrive og diskutere metoder som er benyttet i publiserte \\ observasjonsstudier om overdiagnostikk og dødelighet etter innføring av organisert mammografiscreening \\ i Norge.
}

Mammografiprogrammet startet i fire fylker i 1995/96 og ble gradvis utvidet til å omfatte alle landets fylker i 2004 (1). Hovedformålet med mammografiscreening er å redusere brystkreftdødeligheten. Overdiagnostikk, definert som brystkreft som ikke ville blitt diagnostisert i kvinnens levetid dersom hun ikke var blitt invitert/ hadde møtt til screening (2), ses som den største ulempen.

\section{Metodiske utfordringer}

Det er mange metodiske utfordringer knyttet til evaluering av organiserte screeningprogrammer. Det bidrar til at forskerne kommer frem til ulike svar (3-6). Feltet er preget av store uenigheter og har vært gjenstand for mye debatt, også i Tidsskriftet (7, 8). Jeg vil her konsentrere meg om utfordringene knyttet til detaljnivået på dataene og lengden på oppfølgingstiden i de norske publikasjonene. Dette har vært kommentert for noen av studiene tidligere (9-11), men systematiseres og illustreres her ved nye beregninger og visuell fremstilling.

Flere andre faktorer er også avgjørende for de ulike resultatene (3-6), deriblant om effekten evalueres i et samfunnsperspektiv (for inviterte kvinner) eller i et kvinneperspektiv (for møtte kvinner), hva man forutsetter om situasjonen uten screening, hvilket mål som brukes på overdiagnostikk, om

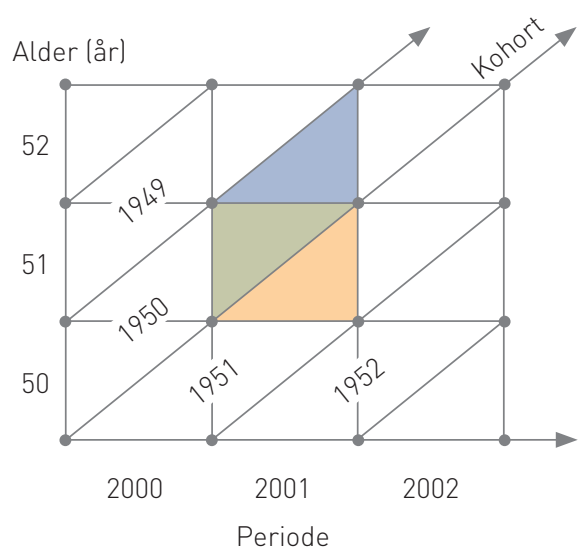

Figur 1 Kvinner inviteres etter fødselskohort (parallellogram) i Mammografiprogrammet. Tilnærming med alder (kvadrat) vil føre til upresise resultater. Eksemplet illustrerer hvordan kvinner født 1950 og invitert i 2001 ikke korrekt kan tilnæmes som 51 år gamle kvinner duktalt carcinoma in situ er inkludert $i$ analysene eller ikke og om det er totaldødelighet eller brystkreftdødelighet som studeres.

\section{Design og data}

Det er to hovedtyper data: data på gruppenivå og data på individnivå. I studier der man bruker data på gruppenivå (økologiske studier), er det mer begrensede muligheter til å kontrollere for eventuelle konfunderende faktorer enn i studier der man anvender individdata som studieenhet (12). Dersom man bruker summariske tall som individdata, må man ha kontroll på de feil det kan medføre.

Kvinner i fødselskohorter som samsvarer med alderen 50-69 år inviteres til Mammografiprogrammet hvert annet år. På bakgrunn av to års screeningintervall og tidspunkt for fylkesvis innføring (opplysninger fra Kreftregisteret) vil den faktiske alder ved invitasjonstidspunktet variere fra 48 år til 73,3 år (falkappendiks). For å unngå feilklassifisering av kvinnenes invitasjonsstatus (invitert/ikke invitert) må data betraktes ut fra fødselskohort (parallellogrammer), ikke alder (kvadrater), siden kvinnene inviteres etter fødselskohort (fig 1).

\section{Oppfølging}

Ved screening kan diagnosen forskyves fremover i tid. Det forventes at man får en økt forekomst mens screeningen pågår og en reduksjon i forekomst etter endt screening. Lang oppfølgingstid er nødvendig, både for estimering av overdiagnostikk og dødelighet av brystkreft. Studier av overdiagnostikk viser at minst ti år oppfølgingstid etter avsluttet screening er nødvendig for å få med den forventede reduksjonen i forekomst blant screenede kvinner $(4,5)$. Dersom oppfølgingstiden er begrenset, må man ty til modelleringsteknikker for å justere for diagnoseforskyvningen (lead time).

Det tar tid fra (første) invitasjon til brystkreftdiagnose, og det går ytterligere tid før kvinner dør av sykdommen. Data fra Kreftregisteret viser at halvparten av dem som var 50-69 år ved diagnosetidspunktet for klinisk brystkreft og som døde av sykdommen i 1991-95, hadde levd mer enn 5,5 år med sykdommen. Siden formålet med screening er å oppdage svulstene i et asymptomatisk stadium, vil man trenge lengre oppfølgings- tid for å estimere dødelighetseffekten av programmet.

\section{Norske dødelighetsstudier}

Det er publisert resultater fra tre studier på brystkreftdødelighet etter innføringen av Mammografiprogrammet (13-15).

Kalager og medarbeidere beregnet en reduksjon på $10 \% \mathrm{i}$ brystkreftdødelighet for inviterte kvinner sammenliknet med ikke-inviterte (13). De benyttet årsskiftet nærmest fylkets oppstartstdato som tilnærmet invitasjonstidspunkt for kvinnene i den inviterte gruppen. Dette medfører ut fra mine beregninger at en kvinne kan ha blitt klassifisert som invitert inntil 2,5 år før hun fikk sin første invitasjon til programmet (falkappendiks). De betraktet data i forhold til alder (fig 1, kvadrat). Kvinnene ble fulgt til utgangen av 2005, noe som innebærer at gjennomsnittlig oppfølgingstid er 2,2 år fra diagnosetidspunktet (13) og, etter min beregning, om lag 3,5 år fra invitasjonstidspunktet (falkappendiks).

Olsen og medarbeidere beregnet nedgangen i brystkreftdødelighet $\mathrm{i}$ de fire forste fylkene til å være $11 \%$ for inviterte kvinner (14). De fem fylkene som startet sist er brukt som kontrollfylker, mens de ti fylkene som startet i årene 1999-2001, ikke er regnet med. Kvinnene ble fulgt til utgangen av 2008. Dette medfører at gjennomsnittlig oppfølgingstid var 5,9 år fra invitasjonstidspunktet.

Hofvind og medarbeidere utførte en kohortstudie der individdata var basert på eksakt invitasjons- og oppmøtetidspunkt (15). Etter å ha korrigert for selvseleksjon beregnet de reduksjonen i brystkreftdødelighet til å være $43 \%$ for kvinner som møtte til screening, sammenliknet med dem som ikke møtte. Invitasjonseffekten anslo de til å være $36 \%$. Kvinnene ble fulgt til utgangen av 2010, noe som gir en gjennomsnittlig oppfølgingstid på 8,3 år fra invitasjonstidspunktet og 5,7 år fra diagnosetidspunktet.

\section{Norske overdiagnostikkstudier}

Det er i dag publisert fem studier der man estimerer omfanget av overdiagnostikk etter innføringen av Mammografiprogrammet (16-20). De to eldste $(16,17)$ vil ikke bli omtalt her, da Zahl \& Mæhlen har overlappende data og lengre oppfølgingstid (18). 

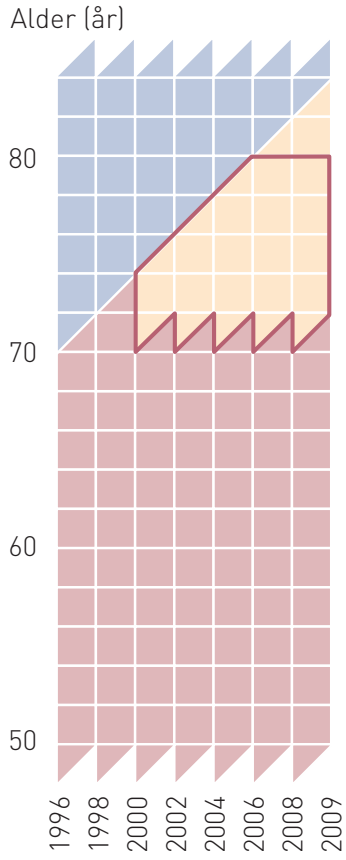

Periode

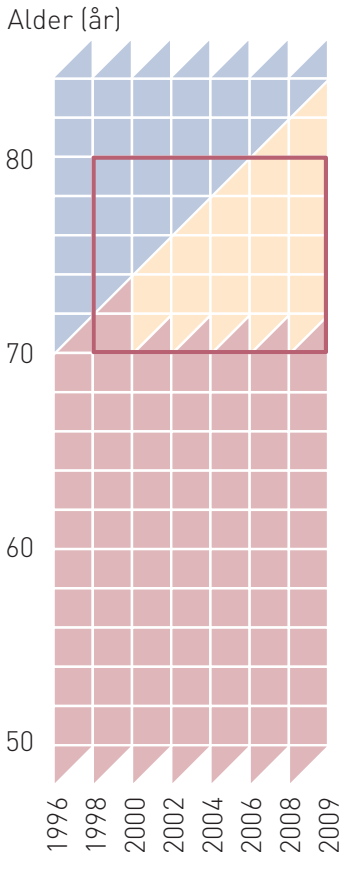

Periode

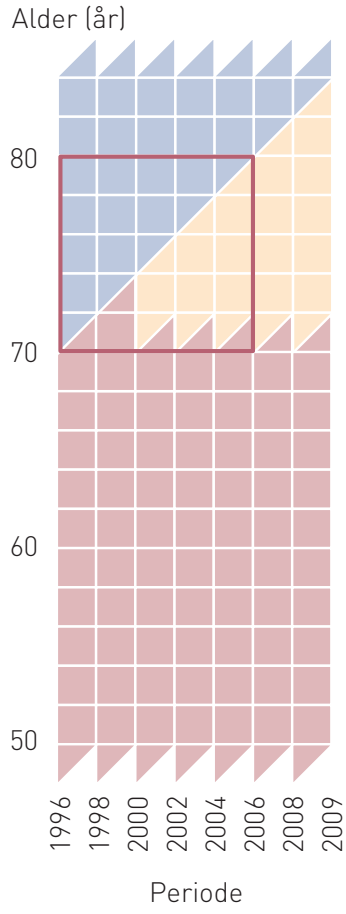

Figur 2 Oppfølging etter screening. Skjematisk illustrasjon av fødselskohorter invitert i de fire første fylkene i Mammografiprogrammet i perioden 1996-2009. Rosa område markerer kvinner som får invitasjon. Gult område markerer kvinner tidligere invitert. Blått område markerer kvinner som aldri ble invitert. Alle tre studiene der man evaluerer overdiagnosikk etter innføring av Mammografiprogrammet inkluderer kvinner i alderen 70 - 79 år i perioden etter screening (18-20). Den røde linjen markerer hvilke avgrensninger forfatterne har gjort. Ut fra populasjonsdata (21) og tidspunkt for oppstart av Mammografiprogrammet i de ulike fylkene lopplysninger fra Kreftregisteret) har jeg beregnet andelen personår innenfor den røde avgrensningen, som er tidligere invitert (falkappendiks). I Falk og medarbeideres studie (20) er det benyttet individdata - $100 \%$ har vært invitert (venstre panel). Zahl \& Mæhlen (18) studerte perioden 1998-2009-52\% har vært invitert (midtre panel). Kalager og medarbeidere (19) studerte perioden 1996-2005-29\% har vært invitert (høyre panel)

Zahl \& Mæhlen har gjort en økologisk tverrsnittsstudie (18). De konkluderte at $50 \%$ av brystkrefttilfellene blant inviterte kvinnene i de fire første fylkene representerte overdiagnostikk. De betraktet tall i forhold til alder (fig 1, kvadrat) til utgangen av 2009 (fig 2, midtre panel). Det medfører ut fra mine beregninger, basert på data fra Statistisk sentralbyrå (21), at $48 \%$ av personårene er feilaktig inkludert i perioden etter screening (falkappendiks). Andelen overdiagnostikk ble målt som ekstra brystkrefttilfeller i forhold til tilfeller uten screening i alderen 50-69 år.

Kalager og medarbeidere rapporterte at $15-25 \%$ av brystkrefttilfellene blant inviterte kvinner var overdiagnostikk (19). De studerte forekomsten av brystkreft blant kvinner i studiegruppen sammenliknet med forekomsten i tre ulike kontrollgrupper. De betraktet kvinnene i forhold til alder (fig 1, kvadrat) til utgangen av 2005 (fig 2, høyre panel). Dette betyr ut fra mine beregninger at $71 \%$ av personårene i de fire første fylkene er feilaktig inkludert i perioden etter screening (falkappendiks). For de øvrige fylkene beregnet jeg at denne andelen var enda høyere, $81-100 \%$ (falkappendiks). Andelen overdiagnostikk ble målt som ekstra brystkrefttilfeller i forhold til tilfeller uten screening i alderen 50-79 år.

Vi utførte en kohortstudie med anonymi- serte individdata (20). Kvinnene ble fulgt fra første invitasjon til utgangen av 2009 (fig 2, venstre panel). Oppmøtene for hver enkelt kvinne ble klassifisert i forhold til deres screeninghistorie. Andelen overdiagnostikk ble estimert for kvinner som følger de nasjonale anbefalingene om ti screeningundersøkelser når de er i alderen 50-69 år. Tidsperspektivet uten screening ble beregnet for alderen 50 år og eldre. Andel overdiagnostikk av brystkreft for inviterte kvinner ble estimert til $10-11 \%$.

Det er store forskjeller mellom disse studiene når det gjelder presisjon på dataene og oppfølgingstiden. Figur 1 illustrerer unøyaktighetene ved å betrakte alder i stedet for fødselskohort når man skal analysere dataene. Når man studerer perioden etter screening, er det en forutsetning at alle inkluderte kvinner har vært invitert tidligere slik at en eventuell reduksjon i forekomst skal kunne inntreffe. Dette er ikke oppfylt for to av studiene (fig 2). Målet på overdiagnostikk er definert for ulike kvinner og for forskjellig aldersgrupper i de tre studiene.

\section{Oppsummering}

Det er mange metodiske utfordringer knyttet til evaluering av Mammografiprogrammet, og resultatene må ses i lys av hvilken metode som er benyttet. Bruk av summariske tall kan medføre feilklassifi- sering av kvinnenes invitasjonsstatus. Det er derfor nødvendig å benytte individdata. Både ved evaluering av dødelighet og overdiagnostikk trengs lang oppfølgingstid for å gi korrekte estimater.

Artikkelen er basert på prøveforelesning for doktorgraden ved Institutt for klinisk medisin, Det medisinske fakultet, Universitetet i Oslo, 26.9. 2013.

Appendiks på www.tidsskriftet.no/falkappendiks

Jeg takker mine kolleger og veiledere Tor Haldorsen, Solveig Hofvind og Per Skaane for nyttige kommentarer til denne artikkelen.

\section{Ragnhild Sørum Falk}

rs@ous-hf.no

Ragnhild Sørum Falk (f. 1980) er cand.scient i biostatistikk og tok i 2013 doktorgraden på avhandlingen Epidemiological studies of earlystage breast cancer in the Norwegian breast cancer screening program. Hun arbeider ved Oslo senter for biostatistikk og epidemiologi, Oslo universitetssykehus.

Forfatter har fylt ut ICMJE-skjemaet og oppgir ingen interessekonflikter.

Litteratur

1. Hofvind S, Geller B, Vacek PM et al. Using the European guidelines to evaluate the Norwegian Breast Cancer Screening Program. Eur J Epidemiol 2007; 22: 447-55.

2. Day NE. Overdiagnosis and breast cancer screening. Breast Cancer Res 2005; 7: 228-9.

3. Marmot MG, Altman DG, Cameron DA et al. The benefits and harms of breast cancer screening: an independent review. Br J Cancer 2013; 108: 2205- 40 .

4. Duffy SW, Parmar D. Overdiagnosis in breast cancer screening: the importance of length of observation period and lead time. Breast Cancer Res 2013; 15: R41.

5. de Gelder R, Heijnsdijk EA, van Ravesteyn NT et al. Interpreting overdiagnosis estimates in population-based mammography screening. Epidemiol Rev 2011; 33: 111-21.

6. Puliti D, Duffy SW, Miccinesi G et al. Overdiagnosis in mammographic screening for breast cancer in Europe: a literature review. J Med Screen 2012; 19 (suppl 1): 42-56.

7. Hofvind S. Organisert mammografiscreening flere fordeler enn ulemper. Tidsskr Nor Legeforen 2013; 133: 619-20.

8. Zahl PH. Informasjonen om mammografiscreening er ikke nøytral. Tidsskr Nor Legeforen 2013 133: $1557-8$

9. Duffy SW, Smith RA. More on screening mammography. N Engl J Med 2011; 364: 283.

10. Haldorsen T, Tretli S, Ursin G. Overdiagnosis of invasive breast cancer due to mammography screening. Ann Intern Med 2012; 157: 220.

11. Tretli S, Ursin G. Overdiagnostikk ved mammografiscreening. Tidsskr Nor Legeforen 2012; 132: 1206

12. Benestad HB, Laake P. Forskning: Metode og planlegging. I: Benestad HB, Laake P, red. Forsk ningsmetode i medisin og biofag. Oslo: Gyldendal Akademisk, 2004: 83-113.

13. Kalager M, Zelen M, Langmark F et al. Effect of screening mammography on breast-cancer mortality in Norway. N Engl J Med 2010; 363: 1203-10. 
14. Olsen AH, Lynge E, Njor SH et al. Breast cancer mortality in Norway after the introduction of mammography screening. Int J Cancer 2013; 132: 208-14.

15. Hofvind S, Ursin G, Tretli S et al. Breast cancer mortality in participants of the Norwegian Breast Cancer Screening Program. Cancer 2013; 119 3106-12.

16. Zahl PH, Strand BH, Maehlen J. Incidence of breast cancer in Norway and Sweden during introduction of nationwide screening: prospective cohort study. BMJ 2004; 328: $921-4$

17. Jørgensen KJ, Gøtzsche PC. Overdiagnosis in publicly organised mammography screening programmes: systematic review of incidence trends. BMJ 2009; 339: b2587.

18. Zahl PH, Mæhlen J. Overdiagnostikk av brystkreft etter 14 år med mammografiscreening. Tidsskr Nor Legeforen 2012; 132: 414-7.

19. Kalager M, Adami HO, Bretthauer M et al. Overdiagnosis of invasive breast cancer due to mammography screening: results from the Norwegian screening program. Ann Intern Med 2012; 156: 491-9.

20. Falk RS, Hofvind S, Skaane P et al. Overdiagnosis among women attending a population-based mammography screening program. Int J Cancer 2013; 133: 705-12

21. Statistisk sentralbyrå. Statistikkbanken. Befolkning. Folkemengden. Tabell 07459: Folkemengde etter kjønn og ettårig alder. www.ssb.no/ statistikkbanken/selecttable/hovedtabellHjem. asp?KortNavnWeb=folkemengde\&CMS SubjectArea=befolkning \& checked=true (10.10.2013).

Mottatt 17.12. 2013, første revisjon innsendt 24.1. 2014, godkjent 6.5. 2014. Redaktør: Siri Lunde Strømme.

Publisert først på nett.

Engelsk oversettelse på www.tidsskriftet.no 